\title{
Containing anxiety in the management of constipation
}

\section{A F West, K Steinhardt}

\section{A common problem}

$C^{2}$ hildhood constipation is a common problem to which both paediatric and psychological perspectives can usefully be brought to bear. The case presented here is an extreme example and, as such, shows some of the pitfalls as well as providing a platform for the presentation of a way of understanding multidisciplinary intervention which might facilitate successful management, not only of childhood constipation, but in a broader clinical context.

\section{THE CASE}

\section{Reason for referral}

A 5 year old boy was referred to a child mental health service with phobic avoidance of defecation and refusal to take medication or comply with Malone antegrade continence enemas (ACE). ${ }^{1}$ There was a long standing history of constipation predating the ACE procedure, but anticipated improvements after surgery had failed to materialise.

\section{Background information}

He was a wanted child, but the pregnancy was plagued with hyperemesis and fatigue. His mother, who had experienced problems breast feeding her children by an earlier marriage, bottle fed him from the outset. She became depressed but received no treatment for this. He was perceived as hungry and not easy to settle, and his feeds were thickened with baby rice given from 4 months. By 8 months he was very constipated, producing hard faecal pellets with occasional blood, and screaming when he needed to defecate. Dietary measures were followed by increasingly large doses of bulking and stimulant laxatives. Anal stretch and evacuation of faeces under general anaesthesia produced, according to the hospital notes, an "enormous cast of the rectum" and left him "inconsolable". Appropriate investigations proved normal. At the unusually young age of 2 years, and despite the recommendation of one paediatrician that psychological opinion be obtained, he was admitted for an ACE procedure. It should be noted that this occurred before the publication of case reviews revealing that the ACE carries a relatively poor prognosis in the very young, and in cases of functional constipation. ${ }^{12}$

Following surgery the behavioural and emotional aspects of the problem became more obvious. Medicines, disguised in juice, were spat back. He was reluctant to sit on the toilet after enemas, and was soiling at school. He was clingy, finding it difficult to separate, particularly from his mother. Some of the professionals involved felt that their recommendations had been only partially followed by the parents, while it was the parents' impression that referrals to specialists had been, at each stage, slow and only at their own insistence. They were getting angry with their son, which they knew was counterproductive. They had tried a star chart, rewarding a motion passed in the toilet, but with so few opportunities for reward, this was doomed to failure.

\section{Formulation}

Doubtless the child was, to some degree, physiologically predisposed to constipation. His mother's reluctant early use of bottle feeding and the thickening of the feeds exacerbated the problem and impacted on the mother-infant relationship. Other factors further undermined secure attachment: the pregnancy had been unpleasant. The infant proved to be difficult to settle, and then developed problems in the fundamental area of elimination. His mother was depressed and lacked support. Her own experience of security, adequate up to that point, was not sufficient to cope with the added demands that an unsettled baby brought.

Protective factors were present: he was a much wanted and initially healthy baby. Both parents were committed to meeting his needs. Relationships between family members were positive and healthy. These, however, were not enough to counteract the anxiety aroused by problems emerging at a crucial stage. The child, unable singlehandedly to tolerate the discomfort and anxiety, became avoidant of toileting. In the context of lack of confidence in the (parent and primary care) system he attempted a form of continence and control before he had gained the necessary maturity. Premature independence is often achieved at the expense of other functions, and in this case meant clingy and emotionally immature behaviour in other settings. This may have made it difficult for the parents to adhere to advice which they felt to be overly intrusive and which their son resisted with determination; a difficulty no doubt increased by the parents' sense that the problem was more profound than simply one of constipation.

From a psychological perspective, in the management of constipation we encounter a familiar tension between the need to contain anxiety and the urge to take increasingly intrusive measures of control. In a complex system, versions of a single dynamic commonly exist in each subsystem. In this case the treating system replicated the difficulties of the parenting system: the failure of feeding to produce the desired faeces, was mirrored in the failure of treatment to produce the required improvement. The attachment between the treating team and the family became less secure, just as the attachment between the parents and the child had done. This unsettled the professionals who increased the intrusiveness of their interventions, undermining rather than restoring parental confidence, and maintaining rather than reversing the vicious cycle.

\section{Intervention}

The first priority was to decrease the anxiety and increase the sense of security and competence felt by the system (comprising the child, his parents, and the involved professionals). This was done by making an authoritative claim for time. The parents were told that it was important to let him relax and grow in the confidence that nothing was expected of him that he could not accomplish. He was given weekly individual non-directive play therapy and, as his confidence grew, a behavioural programme was introduced with the aim of desensitising him to his fears, encouraging more functional toileting behaviour, and empowering his parents by supporting them as the principal therapists. He used the toilet without complaint within three months of starting treatment, and after a further two years his ACE was successfully closed.

\section{DISCUSSION}

This case is used to illustrate two important points: firstly, the role of anxiety in creating and compounding physical problems; and secondly, the potential of attachment theory as a 
therapeutic explanatory model in a wide range of situations. Together they argue the importance of psychological thinking early on in the process, either by incorporation of mental health professionals into primary care and general hospital settings, or by the establishment of liaison teams.

\section{The reassurance of normal functioning}

The achievement of bowel and bladder control is generally taken to be a sign of healthy development. Parents pay close attention to the bowel habits of their young children, and deviation from what they consider to be normal can raise anxiety and lead to consultations with health professionals. Low tolerance of anxiety results in increased sensitivity to deviation from the accepted norm and a low threshold for efforts at imposing control. Treatment reassures by promising a restoration of normal functioning, or at least something resembling it. Investigation may offer a reassuring rationale for treatment, but may also independently reassure the clinician by identifying specific explanatory pathology (positive findings sometimes perversely reassuring us more than negative). The effect on parents of investigation is more ambiguous. Intrusive control compounds the problem when it encounters oppositional autonomy, likely to arise, consciously or unconsciously, in some temperaments more than others, and at certain developmental stages. The drive for oppositional autonomy may be reduced by sensitive timing and dosing of physical treatments, but was increased in this case by unusually reactive surgical management.

\section{Attachment and childcare}

Successful parenting provides a secure base from which the infant can explore their environment with confidence. ${ }^{3}$ If that base fails, then healthy development, which is a form of exploration, can falter. Quality of attachment can be affected by temperamental and physical characteristics of the child, the mother's own early attachments, maternal illness such as depression, as well as the availability and quality of supports within and around the parenting system. ${ }^{4}$ Mary Ainsworth and others have divided attachment relationships into four main categories. ${ }^{5}$ Observing the behaviour of 12-20 month old infants with their mothers, Ainsworth subjected them to a standardised sequence of separations and reunions and identified initially three patterns of attachment, which she called secure, avoidant, and ambivalent. A fourth, called disorganised, was subsequently added after further observation and research, and the area is a developing one. A couple of things need to be pointed out: sufficiently healthy development can occur within a relationship that might not be classified as secure. There is an important distinction between insecure patterns of attachment and attachment disorder. ${ }^{6}$ Finally, it should be made clear that in the context of this case strict classification is inappropriate. The child was of an age at which Ainsworth's procedure would have been inappropriate, and it was not done. When the phrase "securely attached" is used outside the context of Ainsworth's procedure it becomes a more general assessment, derived from a wider range of observations. We are using attachment security, not as a category but as a continuum.

\section{Attachment and therapy}

Byng-Hall $^{7}$ has eloquently described how, as in the healthy parent-child relationship, a therapeutic relationship can provide a temporary secure base from which the family can make the necessary exploratory steps to recovery. The therapist should aim to provide this base, whatever therapeutic method they espouse. Most clinicians will provide this to some extent, even in predominantly somatic treatments, using a host of behaviours and skills. These may be learned or inherent; deliberate or unwitting. They include availability, predictability, and accurate empathy.

\section{Liaison work}

Interventions and expertise explicitly addressing emotional and psychological issues are needed where there is insufficient security within and around the patient system. Published guidelines and algorithms are often at their most detailed and explicit in areas where predictable responses are still being obtained. Psychological or emotional factors tend to make brief, vague, arcane, or late appearances when predictability fails. $^{8-11}$ This often leads, rather late in the day, to a transfer, as opposed to a sharing, of care. In fairness this practice may also partly reflect a lack of psychological professionals working within general hospital and primary care settings.

We recommend, firstly, an understanding that the term "psychosomatic" describes a continuum, and not a dichotomy. People do not become psychosomatic at a discrete point in the process. Professionals with mental health training and experience therefore have a role within the general medical setting. If referral is necessary, it should not depend on the problem being "psychosomatic", but on a lack of sufficient resources within the system to contain the necessary anxiety.

Factors associated with or implying attachment difficulties, either in the patient system or between the patient system and the treating team, should accelerate the involvement of the liaison service We would hope to see discussion with liaison professionals happening as part of the clinic routine, rather than as a step taken when all else has failed.

Arch Dis Child 2003;88:1038-1039

Authors' affiliations

A F West, PPALS, Berkshire Healthcare Trust, UK

K Steinhardt, Department of Paediatric Psychology, Oxford Raddliffe Hospital, UK

Correspondence to: $\operatorname{Dr}$ A F West, Wokingham CAMHS, Wokingham Hospital Clinic Building Barkham Rd, Wokingham RG41 2RE, UK; Andrew.West@berkshire.nhs.uk

\section{REFERENCES}

1 Malone PSJ, Curry Jl, Osborne A. The antegrade continence enema procedure why, when and how? World J Urol 1998:16:274-8.

2 Curry JI, Osborne A, Malone PSJ. The MACE Procedure: experience in the United Kingdom. J Pediatr Surg 1999;34:338-40.

3 Bowlby J. The making and breaking of affectional bonds. Aetiology and psychopathology in the light of attachment theory. Brit J Psychiatry 1977; 130:201-10.

4 Belsky J. Interactional and contextual determinants of attachment security. In: Cassidy J, Shaver PR, eds. Handbook of attachment. New York/London: The Guilford Press, 1999:249-64.

5 Weinfeld NS, Sroufe LA, Egeland B, et al. The nature of individual differences in infant-caregiver attachment. In: Cassidy J, Shaver PR, eds. Handbook of attachment. New York/London: The Guilford Press, 1999:68-88.

6 Zeanah CH, Mammen OK, Lieberman AF. Disorders of attachment. In: Zeanah $\mathrm{CH}$, ed. Handbook of infant mental health. New York/ London: The Guilford Press, 1993:332-49.

7 Byng-Hall J. Creating a secure family base: some implications of attachment theory for family therapy. Fam Proc 1995;34:45-58.

8 Poenaru D, Roblin N, Bird M, et al. The pediatric bowel management clinic: initial results of a multidisciplinary approach to functional constipation in children. J Pediatr Surg 1997:32:843-8.

9 Felt B, Wise CG, Olson A, et al. Guideline for the management of pediatric idiopathic constipation and soiling. Arch Pediatr Adolesc Med 1999; 153:380-5.

10 Baker SS, Liptak GS, Colletti RB, et al. Constipation in infants and children: evaluation and treatment. J Pediatr Gastroenterol Nutr 1999:29:612-26.

11 Collier J, ed. Managing constipation in children. Drug and Therapeutics Bulletin 2000;38(8):57-60. 